\title{
A Cortical Substrate for Parkinsonism: A Personal Journey
}

\section{Gordon W. Arbuthnott* and Marianela Garcia Munoz}

Okinawa Institute of Science and Technology Graduate University, Kunigami-Gun, 904-0495, Japan

\begin{abstract}
We first started thinking that cortex must be important in Parkinson's disease when Alan R. Crossman did some experiments in rats, showing transient reductions in 6-hydroxydopamineinduced spontaneous turning behavior after cortical lesions [1]. The experiments were elegant, but the lesions were large and did not block the turning, suggesting a kind of competition rather than a causal influence of cortex in the turning behavior. Similar conclusions plagued the many attempts to decide which of the brainstem pathways were the substrate of the turning behavior that followed the destruction of dopamine cells unilaterally, for review see, Arbuthnott and Wright [2]. However, as we finished a study of the anatomy of the basal ganglia [3] we concluded that the final output from the striatum came through the output nuclei of the basal ganglia: the globus pallidus pars interna (entopeduncular nucleus in rodents) and the substantia nigra pars reticulata, to a small nucleus in the ventral thalamus (ventromedial -VM- in the rat). Tracing the output from that nucleus brought us back to layer 1 of the cortex, close to where the search started in layer $\mathrm{V}$ [3]. This result had the basal ganglia appearing to be a loop 'linking' layer 5 to the superficial level of the cortex. Not a very likely scenario, nevertheless it did prepare us to look for an involvement of cortex in the consequences of dopamine destruction. Furthermore, the evidence was already there, the striatal spiny projection neurons (SPNs) that carried the first stage of the basal ganglia output, have cortical synapses on the spines [4]. When we studied the electron microscopic (EM) anatomy of the striatum without dopamine, there were obvious differences in those SPN spines [5-7]. There were fewer of them: we counted them stereologically in serial EM sections and found statistically fewer spines when the dopamine had been removed. As the theory about the differences in the two output pathways from the striatum developed, we started

\section{Publication History:}

Received: December 18, 2018

Accepted: December 27, 2018

Published: December 29, 2018

\section{Keywords:}

Parkinson's disease, Cortex, Dopamine signaling, Surgery, Electroencephalogram

more convincing argument resulted from the discussion with Dieter Jaeger that saw me working with his team on the substrate of deep brain stimulation (DBS) [18]. The justification had many aspects, but as neurophysiologists we had struggled with the problem of what was stimulated by electrical stimuli. Exploring this problem and considering that effective DBS delivers $2.5-3.5 \mathrm{~V}$ of $60-90 \mu$ s pulses at high frequency $(130-180 \mathrm{~Hz})$ [19], results from excitability 'strengthduration' curves were interesting: a $50 \mu$ sulse was very unlikely to stimulate anything that was not myelinated, therefore an action on the subthalamic nucleus (STN) cells themselves, was an improbable result and magnified since those cells could fire faster than the $130 \mathrm{~Hz}$. Therefore, we agreed that the likeliest substrate for stimulation was the presence of corticofugal fibres that run past the simulating electrodes. Our experiments showed that stimulation in the STN of rats, clearly induced antidromic potentials intracellularly recorded from layer $\mathrm{V}$ cells in the motor cortex. Furthermore careful analysis of the evoked potentials, showed that the activity was centered in layer $\mathrm{V}$ and that a possible mechanism of action might be the interruption of the synchronized oscillatory activity in cortex by the antidromic driving [20].
\end{abstract} a long series of experiments where we identified the cells on which the spines were counted. By then, we were not alone and the final publication brought together the laboratories of Susan R. Sesack, Ariel Y. Deutch, Jim D. Surmeier, and ourselves [8]. It may be that we missed some dopamine D1 cells that were also denuded of spines [9], but the major effect was robust across all our studies. Therefore, damage to the dopamine input to the striatum, somehow spread to the cortical synapses on the spines of the SPNs. We did most of the work on rats but we also checked that the effect occurred in Parkinsonian patients. In fact, in post mortem human brain the effects were even more marked, with a $27 \%$ reduction in spine numbers compared with the $15 \%$ in the rats [10].

Our results had two consequences that had to be explored: firstly there were many more spines lost than originally had dopamine synapses on them: an idea that supported Fuxe and Agnati's idea about volume transmission of dopamine signaling $[11,12]$. Secondly, such a denervation must have consequences for the cortical involvement in basal ganglia functions and indeed, dopamine functions. A series of experiments that were the beginning of a longterm collaboration between myself and Jeff Wickens showed that in slices of the rat corticostriatal system we could convert the usual long-term depression that followed tetanic trains of cortical input, into long-term potentiation of the corticostriatal synapses [13]. This introduction did little except prepare us to look for the major action of dopamine to be expressed in the corticostriatal synapses, an idea that had been around for some time [14-17]. On the other hand, a

Two other pieces of evidence encouraged us, the first was the discovery of human data of antidromically generated slow waves in patients undergoing DBS, as recorded during surgery for the placement of electrodes [21-23], and the second a publication using not electrical but optogenetic manipulations of STN in 6-hydroxydopaminelesioned mice. Exciting or inhibiting STN neurons did not recover the animals, but high frequency stimulation of the cortical layer $\mathrm{V}$ cells in Thy1-cre rodents did release the animals from the results of the lesions, by relieving bradykinesia and increasing distance and speed of locomotion [24]. Optogenetic techniques have been improved but the result is still the same [25], except that the important part of the stimulation might be the 'hyperdirect pathway' from cortex directly to the STN [26-27], rather than the whole corticofugal axon bundle. In the meanwhile, we had shown with different collaborators that the threshold for recovery of motion in rats made akinetic by dopamine blockade, was the same as that of the cortical antidromic wave $[28,29]$. Finally, in freely moving animals, we could demonstrate

"Corresponding Author: Prof. Gordon W. Arbuthnott, Okinawa Institute of Science and Technology Graduate University, Kunigami, Okinawa 904-0495, Japan; E-mail: gordon@oist.jp

Citation: Arbuthnott GW, Garcia Munoz M (2018) A Cortical Substrate for Parkinsonism: A Personal Journey. Int J Clin Res Trials 3: 130. doi: https://doi. org/10.15344/2456-8007/2018/130

Copyright: (C) 2018 Arbuthnott et al. This is an open-access article distributed under the terms of the Creative Commons Attribution License, which permits unrestricted use, distribution, and reproduction in any medium, provided the original author and source are credited. 
the synchronization of cortical neuronal firing in lesioned animals and the desynchronization that resulted from stimulation in STN, that also drove the cortical layer $\mathrm{V}$ neurons antidromically. The antidromic activity was stochastic because of on-going activity in freely moving animals, but high rates of antidromic driving, effectively desynchronized the electroencephalogram (EEG) [30]. Later there were some modelling studies that supported the likelihood that the antidromic activity was most effective in desynchronizing the EEG oscillations, [31,32]. We wrote a summary of this series of experiments for a conference in Dusseldorf in 2017, with the idea that not many people had heard of the results [33]. Since then, there have been several research papers about the 'early response' from the cortex to single pulses of DBS $[34,35]$ with the extra, that even effective pallidal stimulation for Parkinson's disease, also involved the same 'fast response' and there is even a suggestion that without frontal cortical invasion, DBS is less effective [36]. Not surprisingly the EEG field evoked responses have been used as a means of identifying the effect STN site for stimulation [37].

An interesting engineering development might make for a critical test of the idea, by placing a pair of stimulating electrodes that would make stimulation of the 'internal capsule' more difficult [38]. Clinical papers have investigated the best site in the STN for DBS [39] and two recent papers have suggested that its efficacy may separate Parkinson's disease into categories by length and severity of the disease [40], or even of disease subtypes while off medication according to the Unified Parkinson's disease Rating Scale [41]. There has been a resurgence of information about beta power modulation within high beta frequency bands [42-45], and in deep brain structures during DBS [46-48]. There have also been interesting ideas both in modelling papers reviewed recently by Humphries et al. [49] and recordings in vitro by Aparicio-Juarez et al. [50], where cortical stimulation is sufficient to re-normalize, at least partially, the abnormal firing patterns in the striatum that develop after 6 hydroxydopamine treatment $[51,52]$. On the other hand, the detailed anatomy of the non-human primate cortico-subthalamic pathway, suggests that cortical efferents send axonal branches not only to STN, but also down stream to the red nucleus and zona incerta [53]. A recent publication suggests a new method of stimulation deep in brain without invasive electrode surgery at least in mice [54]. Taking advantage of the neuronal lowpass filter, electric fields can be delivered at frequencies too high to excite neurons individually, but in combination such electric fields provide frequencies low enough for some neurons, they can activate hippocampal neurons without the overlying cortical neurons [54]. Some serious challenges need to be overcome before this method can be applied to human brain, but the principle seems to work in the smaller, thinner skulled, rodent brain.

The influence of Parkinson's disease in cortical physiology and anatomy has been evaluated in some studies that have emphasised the role of motor cortex in the disease [55-57,47,41]. These studies indicate that as the disease progresses there are consequences for the cortex. Can cortical stimulation replace DBS? Probably not, although the original test in monkeys seemed promising [58-59] and there is a reasonable positive review article [60] although it cannot be said to be a mainstream treatment.

Finally, the cortical involvement in Parkinson's disease has as long a history as the discovery of cognitive effects of the disease. To my surprise and far from my cautious attribution of cortical disturbances to the symptoms of the disease, Jose A. Obeso has recently suggested cortical malfunction as the cause $[61,49]$. Such an initial influence of cortex on the symptoms has the obvious advantage of helping with the problem of the early stage of the disease in patients. The initial signs are nearly always localized and often to one side and to a few motor acts. It is hard to see how the diffusely projecting dopamine system could result in such localized dysfunction. On the other hand, cortical lesions certainly have well described local actions as for example seen following a stroke. There remains only the way to link the cortical malfunction with the dopamine system and Obeso's surprising and thought provoking suggestion is that local overactivity in corticofugal pathways might pass on, or perhaps even initiate, synuclein overproduction in dopamine terminals that could be passed back to destroy the whole neuron. There are gaps for sure, but this explanation of a cortical source of the disease, rather than the symptoms appearing after the dopamine loss, seems reasonable and may even suggest new therapies.

\section{Competing Interests}

The authors declare that they have no competing interests.

\section{References}

1. Crossman AR, Sambrook MA, Gergies SW, Slater P (1977) The neurological basis of motor asymmetry following unilateral 6-hydroxydopamine brain lesions in the rat: the effect of motor decortication. J neurol sciences 34 : 407-414.

2. Arbuthnott GW, Wright AK (1982) Some non-fluorescent connections of the nigro-neostriatal dopamine neurones. Brain research bulletin 9: 367-368.

3. Arbuthnott GW, MacLeod NK, Maxwell DJ, Wright AK (1990) Distribution and synaptic contacts of the cortical terminals arising from neurons in the rat ventromedial thalamic nucleus. Neuroscience 38: 47-60.

4. Kemp JM, Powell TP (1971) The termination of fibres from the cerebral cortex and thalamus upon dendritic spines in the caudate nucleus: a study with the Golgi method. Philos Trans R Soc Lond B Biol Sci 262: 429-439.

5. Ingham CA, Hood SH, Arbuthnott GW (1989) Spine density on neostriatal neurones changes with 6-hydroxydopamine lesions and with age. Brain Res 503: 334-338.

6. Ingham $\mathrm{CA}$, Hood $\mathrm{SH}$, van Maldegem B, Weenink A, Arbuthnott GW, et al. (1993) Morphological changes in the rat neostriatum after unilateral 6-hydroxydopamine injections into the nigrostriatal pathway. Experimental brain research. Experimentelle Hirnforschung 93: 17-27.

7. Ingham CA, Hood SH, Taggart P, Arbuthnott GW (1998) Plasticity of synapses in the rat neostriatum after unilateral lesion of the nigrostriatal dopaminergic pathway. J Neurosci 18: 4732-4743.

8. Day M, Wang Z, Ding J, An X, Ingham CA, et al. (2006) Selective elimination of glutamatergic synapses on striatopallidal neurons in Parkinson disease models. Nat Neurosci 9: 251-259.

9. Suarez LM, Solis O, Aguado C, Lujan R, Moratalla R et al. (2016) L-DOPA Oppositely Regulates Synaptic Strength and Spine Morphology in D1 and D2 Striatal Projection Neurons in Dyskinesia. Cereb Cortex 26: 4253-4264.

10. Stephens B, Mueller AJ, Shering AF, Hood SH, Taggart P, et al. (2005) Evidence of a breakdown of corticostriatal connections in Parkinson's disease. Neuroscience 132: 741-754.

11. Fuxe K, Agnati LF, Harfstrand A, Cintra A, Aronsson M, et al. (1988) Principles for the hormone regulation of wiring transmission and volume transmission in the central nervous system. Springer Verlag.

12. Arbuthnott GW, Wickens J (2007) Space, time and dopamine. Trends Neurosci 30: 62-69.

13. Wickens JR, Begg AJ, Arbuthnott GW (1996) Dopamine reverses the depression of rat corticostriatal synapses which normally follows highfrequency stimulation of cortex in vitro. Neuroscience 70: 1-5.

14. Brown JR, Arbuthnott GW (1983) The electrophysiology of dopamine (D2) receptors: a study of the actions of dopamine on corticostriatal transmission. Neuroscience 10: 349-355. 
Citation: Arbuthnott GW, Garcia Munoz M (2018) A Cortical Substrate for Parkinsonism: A Personal Journey. Int J Clin Res Trials 3: 130. doi: https://doi. org/10.15344/2456-8007/2018/130

Page 3 of 4

15. Barbeito L, Girault JA, Godeheu G, Pittaluga A, Glowinski J, et al. (1989) Activation of the bilateral corticostriatal glutamatergic projection by infusion of GABA into thalamic motor nuclei in the cat: an in vivo release study. Neuroscience 28: 365-374.

16. Garcia-Munoz M, Young SJ, Groves PM (1991) Terminal excitability of the corticostriatal pathway. I. Regulation by dopamine receptor stimulation. Brain Res 551: 195-206.

17. Calabresi P, Pisani A, Mercuri NB, Bernardi G (1996) The corticostriata projection: from synaptic plasticity to dysfunctions of the basal ganglia. Trends Neurosci 19: 19-24.

18. Arbuthnott GW, Li S, Jaeger D (2006) Cortical effects of subthalamic nucleus stimulation: An intracellular study in anesthetized rats. 5th Forum of European Neuroscience. Vienna, Austria.

19. Groiss SJ, Wojtecki L, Sudmeyer M, Schnitzler A (2009) Deep brain stimulation in Parkinson's disease. Ther Adv Neurol Disord 2: 20-28.

20. Li S, Arbuthnott GW, Jutras MJ, Goldberg JA, Jaeger D, et al. (2007) Resonan antidromic cortical circuit activation as a consequence of high-frequency subthalamic deep-brain stimulation. J Neurophysiol 98: 3525-3537.

21. Ashby P, Kim YJ, Kumar R, Lang AE, Lozano AM, et al. (1999) Neurophysiological effects of stimulation through electrodes in the human subthalamic nucleus. Brain 122: 1919-1931.

22. Ashby P, Paradiso G, Saint-Cyr JA, Chen R, Lang AE, et al. (2001) Potentials recorded at the scalp by stimulation near the human subthalamic nucleus. Clin Neurophysiol 112: 431-437.

23. Hanajima R, Ashby P, Lozano AM, Lang AE, Chen R, et al. (2004) Single pulse stimulation of the human subthalamic nucleus facilitates the motor cortex at short intervals. J Neurophysiol 92: 1937-1943.

24. Gradinaru V, Mogri M, Thompson KR, Henderson JM, Deisseroth $K$, et al. (2009) Optical deconstruction of parkinsonian neural circuitry. Science 324 354-359.

25. Sanders TH, Jaeger D (2016) Optogenetic stimulation of cortico-subthalamic projections is sufficient to ameliorate bradykinesia in 6-ohda lesioned mice. Neurobiol Dis 95: 225-237.

26. Nambu A, Takada M, Inase M, Tokuno H (1996) Dual somatotopica representations in the primate subthalamic nucleus: evidence for ordered but reversed body-map transformations from the primary motor cortex and the supplementary motor area. J Neurosci 16: 2671-2683.

27. Brunenberg EJ, Moeskops P, Backes WH, Pollo C, Cammoun L, et al. (2012) Structural and resting state functional connectivity of the subthalamic nucleus: identification of motor STN parts and the hyperdirect pathway. PloS one 7: e39061.

28. Arbuthnott G, Dejean C, Hyland B (2009) Antidromic cortical activity as the source of therapeutic actions of deep brain stimulation? In Tseng, K.Y. (ed) Cortico-subcortical dynamic in Parkinson's disease. Humana Press, New York.

29. Dejean C, Hyland B, Arbuthnott G (2009) Cortical effects of subthalamic stimulation correlate with behavioral recovery from dopamine antagonist induced akinesia. Cereb Cortex 19: 1055-1063.

30. Li Q, Ke Y, Chan DC, Qian ZM, Yung KK, et al. (2012) Therapeutic deep brain stimulation in Parkinsonian rats directly influences motor cortex. Neuron 76: 1030-1041

31. Kang G, Lowery MM (2009) A model of pathological oscillations in the basal ganglia and deep brain stimulation in Parkinson's disease. Conf Proc IEEE Eng Med Biol Soc 2009: 3909-3912.

32. Kang G, Lowery MM (2013) Interaction of oscillations, and their suppression via deep brain stimulation, in a model of the cortico-basal ganglia network. IEEE Trans Neural Syst Rehabil Eng 21: 244-253.

33. Arbuthnott GW, Garcia-Munoz M (2017) Are the Symptoms of Parkinsonism Cortical in Origin? Comput Struct Biotechnol J 15: 21-25.

34. Kelley R, Flouty O, Emmons EB, Kim Y, Kingyon J, et al. (2018) A human prefrontal-subthalamic circuit for cognitive control. Brain 141: 205-216.

35. Miocinovic S, de Hemptinne C, Chen W, Isbaine F, Willie JT, et al. (2018) Cortical Potentials Evoked by Subthalamic Stimulation Demonstrate a Short Latency Hyperdirect Pathway in Humans. J Neurosci 38: 9129-9141.

36. Muthuraman M, Deuschl G, Koirala N, Riedel C, Volkmann J, et al. (2017) Effects of DBS in parkinsonian patients depend on the structural integrity of frontal cortex. Sci Rep 7: 43571
37. Trenado C, Elben S, Friggemann L, Groiss SJ, Vesper J, et al. (2018) Intraoperative Localization of the Subthalamic Nucleus Using Long-Latency Somatosensory Evoked Potentials. Neuromodulation 21: 582-587.

38. van Dijk KJ, Verhagen R, Bour LJ, Heida C, Veltink PH, et al. (2018) Avoiding Internal Capsule Stimulation With a New Eight-Channel Steering Deep Brain Stimulation Lead. Neuromodulation 21: 553-561.

39. Bot $\mathrm{M}$, Schuurman $\mathrm{PR}$, Odekerken VJJ, Verhagen $\mathrm{R}$, Contarino FM, et al (2018) Deep brain stimulation for Parkinson's disease: defining the optimal location within the subthalamic nucleus. J Neurol Neurosurg Psychiatry 89 : 493-498.

40. Stefani A, Cerroni R, Mazzone P, Liguori C, Di Giovanni G, et al. (2018) Mechanisms of action underlying the efficacy of deep brain stimulation of the subthalamic nucleus in Parkinson's disease: central role of disease severity. Eur J Neurosci.

41. Xu C, Zhuang P, Hallett M, Zhang Y, Li J, et al. (2018) Parkinson's Disease Motor Subtypes Show Different Responses to Long-Term Subthalamic Nucleus Stimulation. Frontiers in human neuroscience 12: 365

42. Hirschmann J, Ozkurt TE, Butz M, Homburger M, Elben S, et al. (2011) Distinct oscillatory STN-cortical loops revealed by simultaneous MEG and local field potential recordings in patients with Parkinson's disease. NeuroImage 55: 1159-1168.

43. Steiner LA, Neumann WJ, Staub-Bartelt F, Herz DM, Tan H, et al. (2017) Subthalamic beta dynamics mirror Parkinsonian bradykinesia months after neurostimulator implantation. Mov Disord 32: 1183-1190.

44. Fischer P, Chen CC, Chang YJ, Yeh CH, Pogosyan A, et al. (2018) Alternating Modulation of Subthalamic Nucleus Beta Oscillations during Stepping. J Neurosci 38: 5111-5121.

45. Zavala B, Jang A, Trotta M, Lungu CI, Brown P, et al. (2018) Cognitive control involves theta power within trials and beta power across trials in the prefrontal-subthalamic network. Brain 141: 3361-3376.

46. Torrecillos F, Tinkhauser G, Fischer P, Green AL, Aziz TZ, et al. (2018) Modulation of Beta Bursts in the Subthalamic Nucleus Predicts Motor Performance. J Neurosci 38: 8905-8917.

47. Wang YY, Wang Y, Jiang HF, Liu JH, Jia J, et al. (2018) Impaired glutamatergic projection from the motor cortex to the subthalamic nucleus in 6-hydroxydopamine-lesioned hemi-parkinsonian rats. Exp Neurol 300: 135-148.

48. Zhuang QX, Li GY, Li B, Zhang CZ, Zhang XY, et al. (2018) Regularizing firing patterns of rat subthalamic neurons ameliorates parkinsonian motor deficits. J Clin Invest 128: 5413-5427.

49. Humphries MD, Obeso JA, Dreyer JK (2018) Insights into Parkinson's disease from computational models of the basal ganglia. J Neurol Neurosurg Psychiatry 89: 1181-1188.

50. Aparicio-Juarez A, Duhne M, Lara-Gonzalez E, Avila-Cascajares F, Calderon $V$, et al. (2018) Cortical stimulation relieves parkinsonian pathological activity in vitro. Eur J Neurosci.

51. Jaidar O, Carrillo-Reid L, Hernandez A, Drucker-Colin R, Bargas J, et al. (2010) Dynamics of the Parkinsonian striatal microcircuit: entrainment into a dominant network state. J Neurosci 30: 11326-11336.

52. Jáidar OP, Carrillo-Reid LA, Lazarus M, Arbuthnott GW, Bargas J, et al. (2013) Disruption of both striatal output pathways underlies the behavioral response to dopamine depletion. Society for Neuroscience. San Diego, CA.

53. Coude D, Parent A, Parent M (2018) Single-axon tracing of the corticosubthalamic hyperdirect pathway in primates. Brain structure \& function 223: 3959-3973.

54. Grossman N, Bono D, Dedic N, Kodandaramaiah SB, Rudenko A, et al (2017) Noninvasive Deep Brain Stimulation via Temporally Interfering Electric Fields. Cell 169: 1029-1041.

55. Bologna M, Guerra A, Paparella G, Giordo L, Alunni Fegatelli D, et al. (2018) Neurophysiological correlates of bradykinesia in Parkinson's disease. Brain 141: 2432-2444.

56. Burciu RG, Vaillancourt DE (2018) Imaging of Motor Cortex Physiology in Parkinson's Disease. Mov Disord 33: 1688-1699.

57. Sharott A, Gulberti A, Hamel W, Koppen JA, Munchau A, et al. (2018) Spatiotemporal dynamics of cortical drive to human subthalamic nucleus neurons in Parkinson's disease. Neurobiol Dis 112: 49-62.

58. Drouot $X$, Oshino S, Jarraya B, Besret L, Kishima H, et al. (2004) Functional recovery in a primate model of Parkinson's disease following motor cortex stimulation. Neuron 44: 769-778. 
Citation: Arbuthnott GW, Garcia Munoz M (2018) A Cortical Substrate for Parkinsonism: A Personal Journey. Int J Clin Res Trials 3: 130. doi: https://doi. org/10.15344/2456-8007/2018/130

Page 4 of 4

59. Senova S, Poupon C, Dauguet J, Stewart HJ, Dugue GP, et al. (2018) Optogenetic Tractography for anatomo-functional characterization of cortico-subcortical neural circuits in non-human primates. Sci Rep 8: 3362.

60. Lavano A, Guzzi G, DE Rose M, Romano M, Della Torre A, et al. (2017) Minimally invasive motor cortex stimulation for Parkinson's disease. Neurosurg Sci 61: 77-87.

61. Foffani G, Obeso JA (2018) A Cortical Pathogenic Theory of Parkinson's Disease. Neuron 99: 1116-1127. 